\title{
Questes
}

vestes Revue pluridisciplinaire d'études médiévales

$20 \mid 2011$

Maris et femmes

\section{Maris et femmes : conclusion}

\section{Diane Chamboduc de Saint Pulgent et Blandine Longhi}

\section{OpenEdition}

\section{Journals}

\section{Édition électronique}

URL : https://journals.openedition.org/questes/1841

DOI : 10.4000/questes. 1841

ISSN : 2109-9472

\section{Éditeur}

Les Amis de Questes

\section{Édition imprimée}

Date de publication : 15 février 2011

Pagination : 101-104

ISSN : 2102-7188

\section{Référence électronique}

Diane Chamboduc de Saint Pulgent et Blandine Longhi, « Maris et femmes : conclusion », Questes [En ligne], 20 | 2011, mis en ligne le 01 janvier 2014, consulté le 26 août 2021. URL : http:// journals.openedition.org/questes/1841 ; DOI : https://doi.org/10.4000/questes.1841 


\section{Conclusion}

\section{Diane ChAmBOduc DE SAINT PULGENT et Blandine LONGHI}

Les différentes communications proposées dans ce bulletin confirment le point de départ de notre réflexion: les relations matrimoniales sont au Moyen Âge un sujet peu présent dans les textes, de quelque nature qu'ils soient. Ce constat se vérifie tout particulièrement dans les sources historiques, qui se refusent la plupart du temps à envisager l'existence d'une coopération au sein des couples pour se concentrer sur les activités des seuls maris. Cécile Becchia montre que les épouses des hommes de pouvoir n'apparaissent dans aucun des documents concernant la gestion de la vie politique dijonnaise au $\mathrm{XV}^{\mathrm{e}}$ siècle. Les analyses de Diane Chamboduc de Saint Pulgent aboutissent à la même conclusion dans le domaine économique : les sources judiciaires et fiscales omettent le plus souvent de préciser l'activité professionnelle des femmes lucquoises au $\mathrm{XIV}^{\mathrm{e}}$ siècle, mésestimant ainsi leur place dans l'artisanat de la soie qui assure la richesse de la ville. Ce parti pris idéologique est également visible dans la littérature, qui, si elle aime parfois à s'étendre sur le sentiment amoureux, semble souvent exclure de sa sphère le couple conjugal, peu propice à la fiction et au lyrisme. À ce sujet, Fanny Oudin remarque que, dans la correspondance d'Héloïse et Abélard, influence courtoise et influence cléricale se conjuguent pour refuser au mariage l'accès à la parole poétique. Les échanges de lettres sont admis entre amants ou entre religieux, mais il ne semble pas vraiment y avoir de place pour une littérature épistolaire entre époux. La critique moderne a d'ailleurs tendance à entériner cet état de fait en ne retenant d'Héloïse que la double figure d'amante et d'abbesse, et en ignorant celle de l'épouse. 
Cette occultation de l'existence sociale, économique et littéraire du couple marié est bien sûr liée au problème plus large de la place des femmes dans la société médiévale et doit donc également être envisagée dans une perspective d'histoire des genres. Les registres fiscaux lucquois examinés par Diane Chamboduc de Saint Pulgent témoignent de l'inégalité fondamentale entre les époux et de la primauté accordée aux hommes. L'absence d'autonomie des femmes est symbolisée par le fait qu'elles n'apparaissent dans ces documents que lorsqu'elles ne peuvent pas être représentées par un chef de famille, et elles y sont alors le plus souvent définies par leur relation avec leur tuteur plutôt que par leur identité propre. Ce phénomène vient confirmer les normes édictées par les statuts urbains, qui établissent et définissent la minorité juridique des femmes et leur soumission aux hommes de leur parenté. Par ailleurs, alors que le statut matrimonial est un élément déterminant de l'identité des femmes, il apparait comme une composante moins significative de celle des hommes, ce qui contribue également à reléguer le couple au second plan dans les sources. La réalité du mariage médiéval est donc avant tout celle d'une relation dissymétrique : la femme est dépendante de son mari, ce qui a pour conséquence que la notion de couple est moins opérante que celle de chef de famille pour rendre compte du fonctionnement de la société. Les chansons de geste soulignent à cet égard, à travers des exemples de personnages négatifs, le danger représenté par une femme qui outrepasserait son rôle et oublierait sa position d'infériorité. Blandine Longhi montre ainsi que les relations entre Blanchefleur et Louis, dans le cycle de Guillaume d'Orange, permettent d'exprimer l'angoisse face à une sensualité féminine risquant de détruire la virilité des personnages masculins. L'agressivité de Guillaume s'avère nécessaire pour remettre la reine à sa juste place et pour l'amener à respecter les décisions masculines. 
Pourtant, par-delà les fantasmes et les postulats idéologiques, il semble que le couple conjugal ait en réalité tenu une place importante dans la vie quotidienne médiévale. Si l'on se donne la peine de lire entre les lignes, de partir à la recherche de la présence fugace des épouses dans les sources, on doit leur reconnaître un rôle que le discours officiel leur refuse. Cécile Becchia insiste sur le poids politique que les femmes d'échevins ont pu avoir à Dijon. Outre la fonction de représentation qu'elles assurent aux côtés de leurs époux, il apparaît qu'elles peuvent à l'occasion intervenir dans les affaires de la ville, en usant de leur influence pour orienter les décisions des hommes. Maris et femmes peuvent également collaborer dans leur activité professionnelle. Diane Chamboduc de Saint Pulgent souligne ainsi l'existence, souvent ignorée, des femmes artisans, qui participent donc pleinement à l'entretien du ménage. Il faut enfin rappeler que la contraction même des unions est un acte extrêmement lourd de conséquences sociales et économiques. Le choix d'une épouse implique des transactions patrimoniales et la mise en place d'alliances interfamiliales qui situent le couple au centre des relations sociales médiévales. À Dijon, quelques cas prouvent qu'un mariage peut parfois devenir un enjeu public, cristallisant des conflits latents entre le pouvoir princier et les élites urbaines.

L'importance du couple, si farouchement minimisée dans tous les types de sources, apparaît, grâce à ces exemples, dans toute son étendue. Ce modèle d'union monogamique et indissoluble, que l'Église a mis tant de siècles à imposer, révèle alors ce qu'il est devenu au fil du Moyen Âge : un élément structurant de la société et, d'un point de vue plus intime, un trait définitoire des individus, le lieu d'une solidarité fondamentale, tant économique que juridique et sentimentale, qui favorise la survie des personnes qui composent le couple. La littérature peut témoigner à sa manière de cette conscience de l'importance du lien matrimonial. Le soin 
que mettent les textes à diminuer le rôle des épouses ne peut en effet cacher complètement la préoccupation que constitue le thème de la conjugalité. $L a$ Chanson de Guillaume explore, à travers ses différents personnages féminins, toute la palette des représentations du couple et esquisse les conditions d'une union réussie, dans laquelle l'homme puise une force supplémentaire sans avoir à craindre que sa femme ne le dénature. Héloïse tire quant à elle de son expérience personnelle une réflexion générale sur le mariage en s'interrogeant sur ce qui fonde la légitimité d'une relation: affirmant que la pureté des sentiments et l'absence de convoitise ont plus d'importance que l'aspect officiel et religieux de l'engagement, elle prouve que des questionnements d'une grande modernité existent déjà au Moyen Âge.

Le mariage est donc au centre d'un paradoxe: l'infériorité de la femme et sa soumission à son mari, admises comme des évidences sociales et religieuses, apparaissent pourtant, sur le plan individuel, comme problématiques. La place du couple marié dans la littérature, entre idéalisation et rejet, témoigne des interrogations des médiévaux à ce sujet et prouve que le lien conjugal est, à défaut d'être objet de discours, objet de réflexion. 